\title{
PERCEPÇÃO CORPORAL EM CRIANÇA COM BAIXA VISÃO: RELATO DE CASO DE PROJETO DE EXTENSÃO UNIVERSITÁRIA
}

\author{
Caroline Andréa Siqueira Fisioterapeuta. \\ Luana Ribeiro Nascimento Fisioterapeuta. \\ Gisele Kliemann Bailarina, doutora em Comunicação e \\ Semiótica, professora Adjunta da \\ Universidade Federal do Paraná. \\ Clynton Lourenço Corrêa Fisioterapeuta, professor Adjunto do \\ curso de Fisioterapia da Universidade \\ Federal do Rio de Janeiro, diretor \\ científico da ABRAFIN, coordenador \\ do Grupo de Estudo sobre Doença de \\ Parkinson (GEDOPA).
}

\begin{abstract}
Resumo
Introdução: Trabalhos de extensão desenvolvidos durante a formação de profissionais de saúde tem elevado impacto sobre as comunidades assistidas, porém poucas são as publicações relatando estas experiências. Objetivo: Relatar experiências em um projeto de extensão universitária com objetivo de intervir em criança com deficiência visual estimulando a independência desta na realização de suas atividades rotineiras e aperfeiçoar a percepção corporal e espacial. Metodologia: Relato de experiência. Resultados: Participou do estudo uma criança com baixa visão sem deficiências associadas, frequentadora de uma escola municipal em Matinhos/PR. Foram aplicados os testes Performance Oriented Mobility Assessment (POMA) - versão brasileira e Askevold. Em seguida, foram realizadas 12 intervenções com atividades corporais lúdicas baseadas na dança contemporânea associadas à eutonia. Terminadas as intervenções, os testes foram reaplicados. Desde o pré-teste a criança obteve escore máximo no teste POMA; e no teste de Askevold a criança marcou o ponto do trocânter maior direito levemente afastado e houve modificação da distância entre os pontos referentes à articulação acromioclavicular e curva da cintura, obtendo melhor representação no momento da reaplicação. Houve relato por parte da mãe e da professora de melhor atenção e concentração da criança em atividades classe e extraclasse. Conclusão: As atividades propostas parecem constituir parte das estratégias para estimular a percepção corporal em crianças com deficiência visual e melhorar atenção e participação da criança em atividades no ambiente escolar e domiciliar.
\end{abstract}

Palavras-chave: Percepção de movimento; Intervenção precoce; Dança; Criança; Baixa visão.

\section{BODY PERCEPTION IN CHILDREN WITH LOW VISION: REPORT OF A UNIVERSITY EXTENSION PROJECT}

\begin{abstract}
Introduction: Teamwork extension developed during the training of health professionals has high impact on the communities served, but there are few publications reporting these experiences. Objective: To describe experiences in a university extension project in order to intervene in a child with visual impairment encouraging this independence in performing their daily activities and improve body awareness and spatial. Methodology: Experience report. Results: Participated in the study a child with low vision without disabilities associated frequenter of a municipal school in Matinhos / PR. We applied the Performance Oriented Mobility Assessment Tests (POMA) - Brazilian version and Askevold. Then, there were 12 interventions with bodily recreational activities based contemporary dance associated with eutony. Finished the interventions, tests were reapplied. Since the pre-test the child obtained the maximum score on the test POMA, and testing of the child Askevold marked the point of the greater trochanter, and right away there was slightly modifying the distance between the points on the acromioclavicular joint and bend from the waist, giving better representation upon reapplication. The mother and teacher reported that the children improved on attention and concentration levels in class and extracurricular activities. Conclusion: The proposed activities appear to be part of the strategies to stimulate body awareness in children with visual impairment and improve attention and participation of children in activities at school and home.
\end{abstract}

Keywords: Perception of movement; Early intervention; Dance; Children; Low vision. 


\section{INTRODUÇÃO}

A expressão do ser humano ocorre por meio de comunicação verbal e não verbal, envolvendo percepções psicomotoras de base (manipulação, locomoção, tônus postural) e percepções sensitivas (visual, auditiva, gustativa, olfativa e tátil) e está presente em todos os movimentos que a criança realiza. ${ }^{(1)}$

Na criança novas habilidades motoras são adquiridas, a partir das informações obtidas pela percepção, formando um ciclo que possibilita gerar a cada ação novas informações perceptivas que, por sua vez, permitirão realizar novas tarefas. ${ }^{(2)}$ Deste modo, salienta-se a relevância do estímulo à prática de habilidades motoras em crianças com desenvolvimento típico e nas crianças com deficiências à medida que todos os sentidos do corpo recebem estímulos sensoriais e cinestésicos. ${ }^{(2)}$

Para realização de movimento é necessário ter percepção do corpo, de suas partes e dimensões. Percepção corporal é a figuração do corpo em nossa mente, onde os órgãos dos sentidos contribuem anatômica e fisiologicamente para formação da imagem do corpo, ou seja, da fixação do corpo em nossa mente. O esquema corporal, determinado tanto pela figura visual, quanto pela sensação tátil, contribui para formação da percepção corporal. ${ }^{(1)}$ À medida que se desenvolvem, as crianças passam a denominar e designar partes corporais com maior especificidade. ${ }^{(2)}$

A criança com deficiência visual está sujeita a apresentar baixa atividade motora, tendo poucas experiências tátil-cinestésicas devido à falta de estímulos provenientes da visão. Assim, pode apresentar déficits motores, bem como, alteração na imagem corporal, ${ }^{(3)}$ o que pode acarretar em diminuição de percepção corporal.

O termo deficiência visual engloba conceitos de cegueira e baixa visão, baseado no diagnóstico oftalmológico e consiste na medida da acuidade visual, capacidade de discriminação de formas, por meio de apresentações de linhas, símbolos ou letras em tamanhos diversificados. Baixa visão é definida como significativa alteração da capacidade funcional do canal visual, que não pode ser corrigida por tratamentos clínicos e/ou correções ópticas convencionais, comprometendo a acuidade visual, entre outros fatores. ${ }^{(4)}$

Nesse sentido, o presente estudo buscou proporcionar novas experiências corporais, em criança com baixa visão freqüentadora de uma Escola Municipal de Matinhos/PR, visando estimular a independência desta na realização de movimentos funcionais, ou seja, de atividades rotineiras, promover uso dos sentidos remanescentes, desenvolver ou aprimorar a percepção corporal e espacial, por meio de atividades corporais lúdicas que aliaram conceitos e práticas da dança contemporânea e da eutonia.

\section{MÉTODO}

Este estudo é um relato de experiência, produto de um projeto de extensão universitária, aprovado pela Pró-reitoria de Extensão e Cultura (PROEC) da Universidade Federal do Paraná, protocolo no 57310. A escola contava com seis crianças com deficiência visual e foram incluídas à pesquisa quatro crianças com baixa visão e faixa etária entre seis e doze anos. Não participaram aquelas com deficiência cognitiva e/ou mental, afecções músculo-esqueléticas e/ou neurológicas associadas. Assim, das seis crianças apenas quatro foram avaliadas, pois uma mudou de cidade e a outra se enquadrava nos critérios de exclusão. Contudo, considerando a adesão à proposta oferecida e participação em todas as intervenções, apenas uma criança, de nove anos de idade com diagnóstico clínico de baixa visão, que não apresentava outra deficiência associada participou do projeto. 
Após assinatura de Termo de Consentimento Livre e Esclarecido e Autorização para uso da imagem pelos pais ou responsáveis, foram realizadas observações e avaliações a respeito do equilíbrio, por meio do POMA - Brasil. ${ }^{(5)} \mathrm{O}$ teste consiste em duas etapas: avaliação de equilíbrio e da marcha. Os testes funcionais de equilíbrio visam reproduzir atividades de vida diária, avaliando o comportamento do indivíduo frente às alterações de posição. A avaliação funcional da marcha reflete a segurança e a eficiência do deslocamento no ambiente. Cada item tem pontuação de um (realização de forma atípica) a três (realização adequada), sendo o resultado final 57 pontos (escore máximo). ${ }^{(5)}$ A percepção corporal foi avaliada pelo teste de Askevold, ${ }^{(6)}$ como mostra a Figura 1.

Figura 1- Ilustração dos pontos anatômicos conforme o teste de Askevold ${ }^{(6)}$

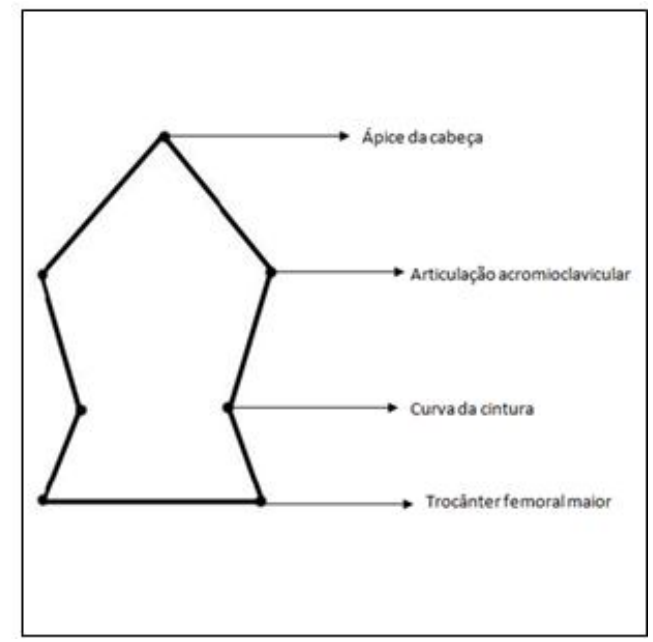

O teste de Askevold consiste em avaliar a percepção de pontos anatômicos específicos (ápice da cabeça, articulações acromioclaviculares direita e esquerda, curva da cintura direita e esquerda e trocânter femoral maior direito e esquerdo) utilizando uma referência autógena a partir da recordação da imagem corporal no espelho. Para isso, a criança avaliada teve que marcar no papel, fixado à parede, o ponto solicitado. ${ }^{(6)}$

Posteriormente, foram realizadas 12 intervenções, com duração de uma hora cada, com atividades corporais lúdicas baseadas nos princípios do método Laban da dança contemporânea, que utiliza fatores de movimento (peso, espaço, tempo e fluência) para construção de movimentos, associadas à eutonia. As intervenções ocorreram de forma espaçada da seguinte maneira: uma no mês de abril, duas no mês de maio, três no mês de junho, duas no mês de agosto, uma no mês de setembro e três no mês de outubro do ano de 2010. Os procedimentos de avaliação e de aplicação das intervenções foram conduzidos pelas acadêmicas de Fisioterapia, autoras deste trabalho.

Da dança contemporânea foram trabalhados os fatores de movimento, peso, espaço, tempo e fluência, visando conhecimento das possibilidades de movimento das várias partes do corpo e possibilidades de locomoção, movimentos articulares, exercícios para percepção e agilidade, aceleração e desaceleração, lateralidade e fluência de movimento. A dança livre foi o estímulo mais empregado, em que a criança foi levada pelos estímulos rítmicos, permitindo que a música o conduzisse a evoluir pelo espaço de acordo com o comando recebido pelas mediadoras. ${ }^{(7)}$ 
Entre os comandos usados destacaram-se: locomover- se pela sala com diferentes partes do corpo em contato com o chão; alterar a velocidade e direção de locomoção (para a direita, esquerda, para frente ou para trás); locomover-se explorando o ambiente, ou seja, explorar cada espaço vazio na sala rolando, rastejando; conduzir um objeto por um determinado trajeto; ter seu movimento direcionado pelo comando das autoras do estudo, devendo imitar o movimento proposto, como em um espelho.

As atividades baseadas na eutonia incluíram: desenvolvimento da imagem corporal; percepção e controle dos diversos graus do tônus muscular, tanto em movimento quanto em posição estática; alongamentos ativos; domínio da distribuição do peso ao sentar-se, ficar em pé e caminhar; movimentos livres relacionados ao espaço, utilizando objetos; as atividades foram realizadas individualmente ou em grupo com participação das autoras. ${ }^{(8)}$ Para isso, a criança recebia, enquanto executava um movimento ou permanecia imóvel deitada em uma superfície, comandos verbais que direcionavam sua atenção para determinadas partes do corpo, fazendo com que percebesse se havia ou não uma maior tensão em uma das partes destacadas; em caso de posição ereta, a percepção de como seus pés tocavam o chão (apoio, suporte de peso), e onde estava localizada cada parte de seu corpo. $^{(8)}$

Já que as intervenções ocorreram com grande intervalo de tempo, ou seja, não foi possível realizá-las de forma contínua, como citado anteriormente, a cada encontro foi realizado um feedback do encontro anterior a fim de resgatar o aprendizado e progredir gradualmente a intensidade e a dificuldade das atividades, com exceção da primeira e segunda intervenções, compostas por apresentação/ familiarização/ avaliação e introdução às atividades. Todas as intervenções foram filmadas para, posteriormente, auxiliar na avaliação dos resultados alcançados.

Após as intervenções e análise dos resultados, foi realizado um encontro com a mãe e professora da criança para transmitir o resultado das atividades propostas. Neste encontro, por meio de uma conversa, foi apresentado o projeto e ilustrada a importância da estimulação motora para melhor desenvolvimento infantil de forma geral. Também foi salientado o relevante papel da família e da escola nesse processo.

\section{RESULTADOS}

No teste POMA - Brasil, quando aplicado pela primeira vez, a criança obteve escore máximo (57 pontos). No teste de Askevold a criança marcou todos os pontos de acordo com modelo proposto, tendo ficado o ponto do trocânter maior direito levemente afastado (Figura 2A). Na reavaliação, o POMA - Brasil continuou com escore máximo. No teste de Askevold o ponto do trocânter maior direito apresentou-se mais alinhado. Também foi observada modificação da distância entre os pontos referentes à articulação acromioclavicular e curva da cintura (Figura 2B). 
Figura 2 - Askevold pré e pós-intervenção

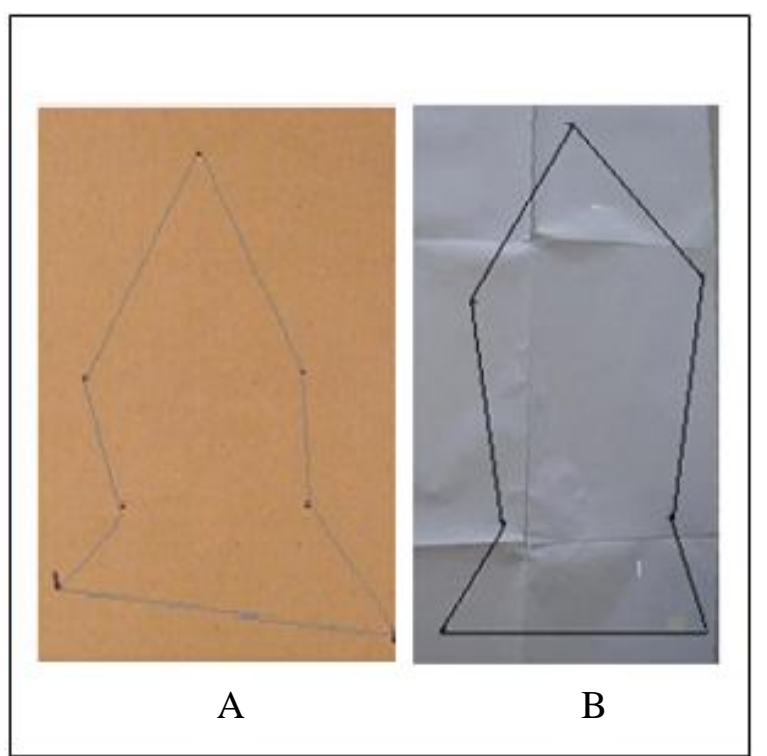

Na Figura A verifica-se maior distancia dos pontos equivalentes aos trocânteres. Observe o ponto equivalente ao trocânter direito mais afastado. Na Figura B verifica-se uma melhor simetria quando comparado à Figura A.

$\mathrm{Na}$ análise qualitativa verificou-se melhor desempenho nas atividades, bem como maior confiança e prontidão na realização de movimentos propostos durante as intervenções. Também foram observados que nas intervenções iniciais a criança tinha dificuldade em desempenhar as tarefas, apresentando poucas estratégias para execução do movimento, o que não foi apresentado ao término destas. No decorrer dos encontros, a criança executou com maior agilidade as tarefas propostas.

Além disso, houve melhora em aspectos comportamentais, como atenção e participação nas atividades escolares e domiciliares, que embora não avaliados como foco deste estudo, foram percebidos na fala da professora da escola municipal e pela mãe da criança, através de encontro a fim de divulgar os resultados das intervenções desenvolvidas. No início das práticas, a criança tinha sua atenção desviada por qualquer estímulo, dificultando a realização das atividades sugeridas. Entretanto, ao final das intervenções, ela era capaz de se manter atenta à atividade que desempenhava, demonstrando maior atenção para execução das tarefas.

\section{DISCUSSÃO}

Por meio de sentidos remanescentes, como o tato e a audição, as crianças com deficiência visual podem reconhecer o meio em que estão inseridas, construindo a imagem do mundo pelo uso desses sentidos. ${ }^{(3)}$ Pelo manuseio de objetos de diferentes texturas, tamanhos e formas, é possível explorá-los, identificá-los e conhecêlos. ${ }^{(4)}$ Deste modo, o tato estimula a atividade cerebral e permite ao indivíduo o conhecimento corporal e do ambiente que o cerca. Por sua vez, a audição é capaz de captar qualquer estímulo vindo do ambiente em todas as direções, e o cérebro tem a função de filtrar as informações sonoras. ${ }^{(4)}$ As consequências motoras da deficiência visual podem ser superadas, caso sejam fornecidas as condições para promoção do desenvolvimento das pessoas com deficiência, capacitando-as e removendo bloqueios atitudinais. ${ }^{(9)}$ 
Por meio da dança é possível reconhecer o movimento do próprio corpo, apropriando-se de parâmetros sensório-motores relacionados à marcha, ao equilíbrio, à força e à flexibilidade. Para as pessoas cegas e com baixa visão, a prática da dança torna-se extremamente relevante pelas interações espaço/temporais e corporais com os processos mentais. ${ }^{(10)}$

Sua estrutura (inter-relação das partes) e estilo (modelo característico e qualidade de seus elementos) podem ser analisados de acordo com tempo, ritmo, dinâmica e uso do corpo. ${ }^{(11)}$ Isso é fundamental para o desenvolvimento de padrões motores e reconhecimento do próprio corpo durante a execução de movimentos, e, portanto, aplicável como atividade para a criança com baixa visão, uma vez que estimula o desenvolvimento de sua percepção auditiva, tátil e cinestésica.

A dança contemporânea, em particular, ultrapassa os limites de técnicas ou movimentos específicos permitindo ao praticante maior autonomia de movimento. ${ }^{(10)}$ Busca a exploração de infinitas possibilidades de utilização do espaço, e pela alternância e variação de movimentos técnicos e livres (este último, no sentido do movimento ser desprendido de regras, e cuja execução remete à espontaneidade e naturalidade) que se evidenciam de forma mais expressiva. ${ }^{(12)}$

$\mathrm{Na}$ atualidade, a combinação entre dança, técnicas terapêuticas, como fisioterapia e técnicas somáticas fornecem bases para a construção de um corpo que possui uma percepção diferenciada de si e do mundo. ${ }^{(13)}$ Dentre as várias práticas somáticas aliadas à dança, a eutonia torna-se relevante ao passo que se trata de uma técnica para controle e equilíbrio do tônus muscular a partir de movimentos que visam estimular o sistema proprioceptivo, possibilitando melhor aprendizado a cerca do próprio corpo e suas limitações. ${ }^{(8)}$

Neste trabalho, a cada intervenção, a criança era desafiada a desenvolver estratégias para atingir as atividades propostas. Foi estimulada a descobrir novas maneiras de se movimentar, ampliando seu repertório motor. Isso pode ser explicado pelo mecanismo de ajuste para assimilação e acomodação das informações, onde a diversificação dos estímulos gera experiências de forma a apresentar para criança desafios cada vez mais complexos, que ela deve ser capaz de resolver de acordo com as suas habilidades. ${ }^{(14)}$

De acordo com o teste POMA - Brasil, verificamos que a criança obteve o efeito teto, com escore máximo também observado na reavaliação, de modo que não observamos alterações relativas ao equilíbrio, uma vez que a criança já apresentava independência na realização das atividades. Desta forma, talvez o instrumento escolhido (POMA) não tenha sido uma ferramenta sensível para detectar tais modificações, o uso de uma análise cinemática ou plataforma de equilíbrio poderiam ter possibilitado uma análise mais minuciosa ou a criança desse estudo não tenha comprometimento do equilíbrio.

No teste de Askevold, o ponto do trocânter maior direito apresentou-se melhor alinhado, o que provavelmente ilustra melhor representação da imagem corporal e, consequente, melhora na percepção corporal. A relação entre a articulação acromioclavicular e a curva da cintura foi modificada comparando o os momentos pré e pós-intervenção. Algumas conexões sinápticas dependem da estimulação sensorial para refinar e estabilizar os circuitos cerebrais, processo conhecido como plasticidade. Nesse sentido, novas experiências podem contribuir para este processo. ${ }^{(15)}$ Uma vez que as atividades realizadas com a criança participante deste trabalho contavam, diversas vezes, com estímulos sensoriais táteis e auditivos, sendo associados aos comandos que direcionavam a atenção a cada parte do corpo, isso pode ter contribuído para novas possibilidades de movimentos e melhor percepção do seu corpo. Além disso, a adequação na realização das atividades funcionais, 
realizadas de maneira lúdica, pode ter contribuído para o sucesso no desempenho da criança nesse teste. De acordo com a teoria dos sistemas dinâmicos, abordada na perspectiva ecológica de desenvolvimento humano, mudanças nas tarefas ou nos objetivos destas, para que sejam apropriadas às características físicas da criança $\mathrm{e}$ do ambiente que a envolve, podem facilitar o desempenho da criança na realização de atividades que antes não exercia. $^{(16,17)}$

Melhor desempenho na execução dos movimentos também foi observado a partir da análise das filmagens. A modificação do padrão de movimento corporal que resulta de percepções e movimentos originários de uma intervenção amplia as possibilidades (percepções e movimentos), proporcionando inovadoras alternativas para o indivíduo durante o processo de vida. ${ }^{(18)}$

As crianças com baixa visão devem experimentar diversas formas de estimulação, tanto na escola como no ambiente familiar, que auxilie na ampliação do repertório de experiências corporais. Variações nas características da tarefa a ser executada, bem como de seu contexto, permite ao aprendiz executar com sucesso uma nova tarefa, uma vez que este deverá construir um conjunto de regras para produzir e avaliar a nova habilidade no momento da execução, proporcionando aumento do repertório motor. ${ }^{(19)}$

Melhora de atenção e maior participação nas atividades escolares e domiciliares, relatada pela mãe e professora da criança, através de entrevista, pode ser explicada pelo fato de o movimento, além de abranger atos motores, assumir uma dimensão social, visto que os movimentos expressivos do corpo e as suas reações tônicas possibilitam à criança exercitar a autonomia de entrar em contato com os outros e buscar uma interação maior. ${ }^{(14)}$ Desta forma, a interação entre as crianças com baixa visão em situações lúdicas proporciona um ambiente favorável às múltiplas elaborações cognitivas das crianças. ${ }^{(14)}$

Durante a prática das atividades lúdicas a criança foi levada a exercitar e ampliar sua autonomia pelas tomadas de decisão solicitadas nas tarefas. A atenção direcionada para resolver cada novo desafio estimulou sua atividade cognitiva de forma a colaborar com o desenvolvimento de uma maior independência tanto motora quanto intelectual. Uma vez que a autonomia é relevante para a sua vida familiar e social, as atividades propostas neste estudo podem ter colaborado para melhora na atenção para execução de atividades escolares e domésticas.

\section{CONCLUSÃO}

O estudo possibilitou uma integração entre o conhecimento produzido na Universidade e sua aplicação na escola pública, num exercício teórico-prático. Além disso, proporcionou à escola e, principalmente à criança, compreensão sobre novas possibilidades de intervenção para estimulação, desenvolvimento e aperfeiçoamento da aquisição motora.

A criança não apresentou alteração do equilíbrio no pré-teste. Quanto ao teste de Askevold, observou-se melhor percepção corporal após o programa de intervenção ora proposto. Também foi observado por análise qualitativa melhora dos aspectos como atenção e participação da criança em atividades solicitadas no ambiente escolar e domiciliar.

São necessários mais estudos com amostra maior e sistematização da frequência das intervenções aqui relatadas para confirmar ou não a indicação dessas técnicas descritas nesse estudo em crianças com deficiência 
visual, bem como, utilização de outras ferramentas e variáveis para melhor compreensão dos fenômenos relacionados à essa população.

\section{AGRADECIMENTOS}

Agradecemos a todos que colaboraram, de forma direta ou indireta, para a realização deste trabalho.

\section{REFERÊNCIAS}

1. Nanny D. O ensino da dança na estruturação/expansão da percepção corporal e auto-estima do educando. Fitness \& Performance Journal. 2005; 4: 45-57.

2. Haywood KM, Getchell N. Desenvolvimento motor ao longo da vida. 5aed. Porto Alegre: Artmed, 2010.

3. Sena DSF. A psicomotricidade na vida da criança portadora de deficiência visual: uma abordagem inclusiva (Monografia). Rio de Janeiro: Universidade Cândido Mendes, 2005.

4.Ventorini SE. A experiência como fator determinante na representação espacial do deficiente visual (Dissertação). Rio Claro: Universidade Estadual Paulista. 2007.

5. Gomes GC, Diogo MJE, Magalhães LC. Tradução, adaptação transcultural e exame das propriedades de medida da escala "performance-oriented mobility assessment" (poma) para uma amostragem de idosos brasileiros institucionalizados (Dissertação). Campinas: Universidade Estadual de Campinas, 2003.

6. Martins RO. A prática do Isostretching na melhora da percepção corporal. Cascavel: Curso de Fisioterapia, 2004.

7. Laban R. Dança educativa moderna. São Paulo: Ícone; 1990.

8. Vishnivetz B. Eutonia: Educação do corpo para o ser. São Paulo: Summus, 1995.

9. Silva MA, Batista CG. Mediação semiótica: estudo de caso de uma criança cega, com alterações no desenvolvimento. Psicologia: Reflexão e Crítica. 2007 (1): 148-156.

10. Cazé CMJO, Oliveira AS. Dança além da visão: possibilidades do corpo cego. Pensar a Prática. $2008 ; 11$ (3): 293-302.

11. Saraiva KC, Nunes MAL. A dança na contemporaneidade relacionada à metodologia histórico-crítica. Revista Cesumar - Ciências Humanas e Sociais Aplicadas. 2009; 14 (2): 315-338.

12. Rondin JR, Sambugari MRN. Educação do movimento corporal: desafios e perspectivas. Anais do encontro de pedagogia: 40 anos formando educadores; 2007; ISBN: 978-85-7613-123-6: 109-116.

13. Resende CM. Saúde e corpo em movimento (Dissertação). Rio de Janeiro: Universidade Federal do Rio de Janeiro, 2008.

14. Santos LC, Passos JEOS, Rezende ALG. Os efeitos da aprendizagem psicomotora no controle das atividades de locomoção sobre obstáculos em crianças com deficiência da visão. Rev. Bras. Ed. Esp. 2007; 13 (3): 365-380.

15. Papalia DE, Olds SW, Feldman RD. Desenvolvimento humano. 10ªed. São Paulo: McGraw - Hill; 2009.

16. Darrah et al. Context therapy: a new intervention approach for children with cerebral palsy. Developmental Medicine \& Child Neurology. 2011. 
17. Newell KM; Liu YT; Mayer-Kress G. A dynamical systems interpretation of epigenetic landscapes for infant motor development. Infant Behavior \& Development. 2003; 26: 449-472.

18. Tourinho LL, Silva EL. Estudo do movimento e a preparação técnica e artística do intérprete de dança contemporânea. Arte filosofia. 2006; (1): 125-133.

19. Meira Junior CM; Tani G; Manoel EJ. A estrutura da prática variada em situações reais de ensinoaprendizagem. Rev. Bras. Ciên. e Mov. 2009; 9(4): 55-63. 